\title{
Environmental Medicine in Industry
}

\author{
By C. RICHARD WALMER, M.D.
}

$\mathrm{E}$ NVIRONMENTAL MEDICINE in industry may be defined as a specialized form of medical and public health practice which combines with medicine the sciences of engineering, chemistry, toxicology, psychiatry, sociology, statistics, and health promotion. It has as its objective the improvement of physical and mental efficiency of the worker through the application of these sciences to both the worker and his industrial environment. The results should be measured in increased production and better products.

\section{Functions and Benefits}

Among the functions of environmental medicine in industry are physical and mental examinations to determine the fitness of the worker to do a particular job, remedial measures to restore his health and working ability when he sustains occupational injury or illness, preven-

Dr. Walmer has been managing director of the Industrial Hygiene Foundation of America, Mellon Institute, Pittsburgh, Pa., since 1951. He was medical director of the foundation for the preceding 5 years, and from 1941 to 1946 he was consulting toxicologist and an administrator in the medical department, Westinghouse Electric Corporation, Pittsburgh. He presented this paper at the meeting of the Medical Advisory Committee of the National Fund for Medical Education with the Council on Industrial Health of the American Medical Association, December 8, 1953, in Pittsburgh. tive procedures to reduce the possibility of such injuries and illnesses, and education to promote and improve his health and general well-being. Environmental medicine, industrial hygiene, accident prevention, workmen's compensation laws, and various health benefit plans all work together to achieve the goal of physically and mentally healthy workers. In addition, many industrial management components have a secondary, but nonetheless vital, concern with industrial health. These include supervision, job placement, inplant feeding, labor relations, plant security, and various aspects of engineering and purchasing. And the interest of management in industrial health should be shared by the worker, the community, and the entire Nation.

An effective environmental medical program in industry is, of course, beneficial to the employee, the employer, and the community. To the employee, poor health means loss of wages, a reduced period of useful and productive capacity, and the need for making arrangements to provide for himself and his dependents when income fails. Ill, injured, or improperly placed employees mean loss of service, decreased efficiency, low morale, and increased manufacturing cost to the employer. To the community, all of these factors mean decreased prosperity, increased welfare costs, and perhaps labor strife.

Industry generally has been rather slow to realize that environmental medicine can be a potent force and an important focal point in the development of a successful industrial relations program. More visits are made by employees 
to the plant medical facility than to any other segment of industrial relations with the possible exception of the inplant feeding service. Appropriate physical surroundings in the medical department, capable medical personnel, and efficient medical service promote confidence in the company on the part of employees and of applicants for jobs. In fact, the applicant for a job forms much of his first impression of the company during his pre-employment examination, and the sick or injured employee is particularly impressionable during his visits to the medical facility. The attitude of both toward the company can be influenced tremendously by the way the medical department receives them. For this reason, hardly any other component of the company has a comparable opportunity to demonstrate directly the company's industrial relations and to influence the attitude of the worker.

\section{The Industrial Physician}

The success of the medical program will depend largely upon the manner in which it is organized and administered. The industrial physician needs to be more than a good clinician. As a matter of fact, he must have qualifications and training which most good clinicians do not have. For example, he must be an extremely able administrator, and he must have the ability to fit into an organization and work with people. The industrial physician must have an understanding of production problems, the principles of management, and the essentials of personnel work. His clinical knowledge must include a great deal which the average physician in private practice does not ordinarily need to know, such as toxicology and the recognition of hazards in the industrial environment. The physician concerned with environmental medicine in industry cannot make a proper preplacement examination unless he is familiar with the job, its physical demands, and its inherent hazards, as well as the physical capacities and limitations of the employee.

. In other words, the industrial physician needs a working knowledge of chemistry, engineering, psychology, and business administration, as much as he needs clinical acumen. He practices a broad specialty rather than a nar- row one, and, unlike other specialists, the more training he gets, the broader are his horizons and the more capable he is of coping with industrial problems incident to working man.

\section{Environmental Medicine Activities}

The objective of environmental medicine in industry is accomplished through activities which may be roughly classified as follows: $(a)$ evaluation of the employee's physical and mental condition, (b) maintenance of health, $(c)$ provision of medical and surgical care for occupational illness or injury, $(d)$ control of the environment, and $(e)$ research.

The physical and mental evaluation of the employee is based on and derived from the various applications of the medical examination. Thus, the preplacement physical examination, which should also include a mental or psychometric evaluation, is the basis upon which rests the proper selection and placement of potential workers. These examinations provide a baseline for comparison with future examinations of the same individuals and direct attention to minor physical defects which can be corrected before they become serious. They also do much to safeguard the health of fellow employees and to promote an understanding of the value of good personal hygiene. Experience has demonstrated that healthy persons, properly placed, are more productive, safer, and more contented employees. Confused or ill employees have poorer judgment and are more prone to accident. They have a delayed reaction time to stimuli and may frequently miscalculate distances and speed, resulting in a decrease of their efficiency.

The physical examination also plays a prominent part in health maintenance. For this purpose, examinations are made at intervals depending upon the age of the employee, the hazards to which he is exposed, and any previous pertinent findings with respect to his general health. They are adjusted in scope and detail according to the need of each particular person. Probably as important as the examination itself is the opportunity which the program provides for the physician to counsel the employee and for the worker to have an opportunity to present his problems to the physician. More 
(:in often be accomplished in the way of health maintenance by these informal and direct disc'ussions than by group instruction or classroom techniques. Of course, such techniques and devices as bulletin boards, posters, articles in the 'ompany publication, and group discussions accompanied by visual aids are also used.

Medical and surgical care must be prompt and adequate in order to deal properly with onthe-job emergencies which arise from time to time. Here again the industrial physician's training must be such that he will recognize illnesses which may have their origin in the work environment. Just as important, he must know when an illness is not to be ascribed to the effects of materials with which the patient comes in contact. Probably his ability to refer patients to the most able consultants and to evaluate the work of such specialists is more important than his own clinical ability.

Environmental control, or industrial hygiene, requires the assistance of trained personnel, but the physician must be able to understand and utilize this help. The physician need not attempt to be an industrial hygienist, but a good industrial physician must know how the industrial hygienist can help him and when to call upon the hygienist's services. The physician should have a general knowledge of the physiological effects of heat, noise, and fatigue, and he should be entirely familiar with the effects of toxic gases, dusts, fumes, and vapors.

To direct its energies properly and to keep constantly alert to changing situations, environmental medicine in industry must engage in research. It may not engage in fundamental research on its own, but it should at least utilize the services of research organizations so that it will know, for example, the toxic potentialities of the substances or products for which it is responsible. The applied research activities may be simply statistical or epidemiological analyses of the cases coming to its attention so that it may direct its energies to the proper channels.

\section{Prognostications}

As a result of its research, as well as of the other activities outlined, environmental medi- cine in industry tomorrow will progress, I am sure, to the point where the medical department will be recognized as a positive part of the industrial organization. It will be regarded as a part of the production team, and its assistance will be sought, not after some difficult situation has arisen, but in the planning stage, with a view toward prevention of trouble by a careful utilization of forethought and design.

I believe that in the future environmental medicine will be utilized for the protection of the thousands of workers in small plants who today do not have the benefit of such programs. Nearly two-thirds of our industrial workers are employed in plants having fewer than 500 employees, and such plants constitute over 98 percent of the Nation's industrial establishments. These small plants cannot individually establish complete medical departments or environmental health programs. Some way must therefore be found to provide them on a cooperative basis. Even so, the burden of this type of environmental medicine will fall upon the private practitioners, many of whom do not regard themselves as being in any way connected with environmental health. Yet, a recent poll by the American Academy of General Practice indicated that 90 percent of its membership considered that they do some "industrial practice."

This is evidence of a real need for education on the postgraduate level. Some method must be devised whereby the general practitioner can obtain a fundamental knowledge of environmental medicine, particularly as it applies to industry, which will not interfere with his daily practice and will not take an inordinate amount of his time. The various State committees on industrial health, the American Academy of General Practice, and the schools with organized courses in environmental medicine are ready to answer a part of this problem, but, in the long-range view, a working knowledge of industrial medicine as a part of the undergraduate curriculum will do much to prepare the general practitioner for the important part he must play in environmental medicine in industry. 